\title{
Neural Tube Defects: Review of Experimental Evidence on Stem Cell Therapy and Newer Treatment Options
}

\author{
Dhara B. Dhaulakhandi ${ }^{a}$ Seema Rohilla ${ }^{b}$ Kamal Nain Rattan ${ }^{c}$ \\ Departments of ${ }^{\mathrm{a} B i o t e c h n o l o g y}$ and Molecular Medicine, ${ }^{\mathrm{b}}$ Radiodiagnosis and Imaging, and ${ }^{\mathrm{c} P e d i a t r i c}$ Surgery, \\ Post Graduate Institute of Medical Sciences, Pt. B.D. Sharma University of Health Sciences, Rohtak, India
}

\section{Key Words}

Neural tube defects $\cdot$ Myelomeningocele $\cdot$ Stem cells • Induced pluripotent stem cells $\cdot$ Combination therapies

\begin{abstract}
The failure of closure of the neural tube during development leads to malformations called neural tube defects (NTDs). The most common neural malformations in humans include anencephaly, encephalocele, exencephaly, craniorachischisis spina bifida with or without myelomeningocele, lipomyeloschisis, lipomyelomeningocele, meningocele and myelocystocele. Current preventive strategies are mainly based on pharmacologic/folic acid supplementation. However, stem cell-based and other combination approaches may emerge as potential treatment options for NTDs. This review provides an account of experimental evidence on stem cell therapy and newer treatment options for NTDs which have become available in recent years. Copyright $\Theta 2010$ S. Karger AG, Basel
\end{abstract}

\section{Introduction}

Neural tube defects (NTDs) are the result of perturbation in the neurulation process. Neurulation, through a coordinated series of events, gives rise to the neural plate, neural folds and the neural tube which eventually dif- ferentiates and develops into the future brain and spinal cord. Most NTDs arise in anterior and posterior neuropores as they close last. NTDs can be open or closed depending upon exposed or closed neural tissue. Open NTDs (ONTDs) are the result of primary neurulation and may involve any area of the central nervous system (CNS). Closed NTDs are due to defects in secondary neurulation and are mostly confined to the spine. Cranial manifestations of NTDs include myelomeningocele (MMC) (fig. 1, 2), meningoencephalocele (fig. 3, 4), anencephaly, encephalocele (meningocele or meningomyelocele), craniorachischisis totalis, and spinal presentations include spina bifida aperta, myeloschisis, congenital dermal sinus, lipomatous malformations (lipomyelomeningoceles), split-cord malformations, diastematomyelia, diplomyelia and caudal agenesis.

NTDs are complex multifactorial genetic defects involving both genetic and environmental factors. Geography, ethnicity, nutrition, maternal illness, maternal age and parity, previous abortions, multiple gestations, obesity, parental socioeconomic status and parental occupational exposure are important epidemiologic determinants of NTDs. Folate deficiency has been implicated as the major cause of NTDs after teratogens. Toxins and antiepileptic drugs such as valproate and carbamazepine can also induce NTDs. NTDs are often found associated with several other syndromes, chromosomal and single gene disorders, twinning, chromosomal aberrations as

Dhara B. Dhaulakhandi

Post Graduate Institute of Medical Sciences

Pt. B.D. Sharma University of Health Sciences

Rohtak, Haryana 124001 (India)

Tel. +91 941631 2237, Fax +91 21 1109, E-Mail BTMM.submissions@gmail.com 
1

Fig. 1. Lumbosacral meningomyelocele with hypertrichosis.

Fig. 2. Lumbosacral meningomyelocele with exposed meninges.

Fig. 3. Occipital meningoencephalocele with anencephaly.

Fig. 4. Nasal meningoencephalocele.

3

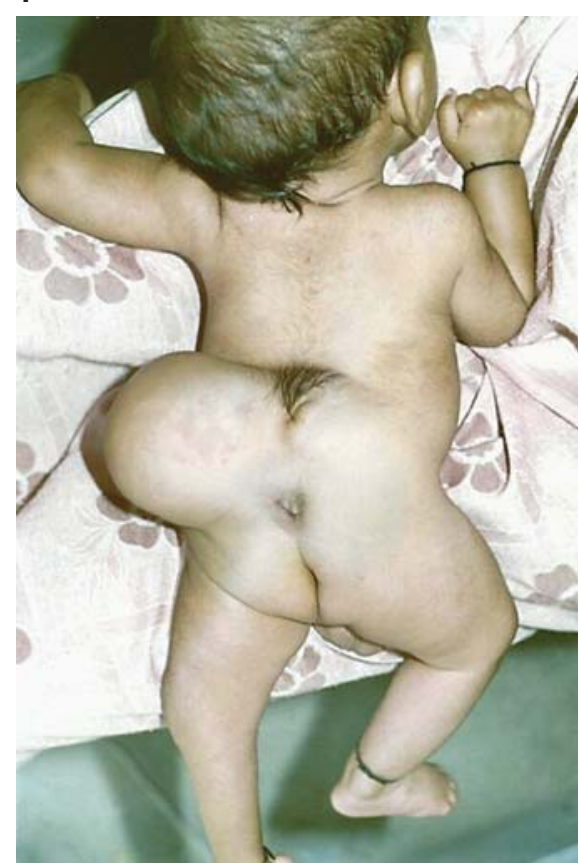

2
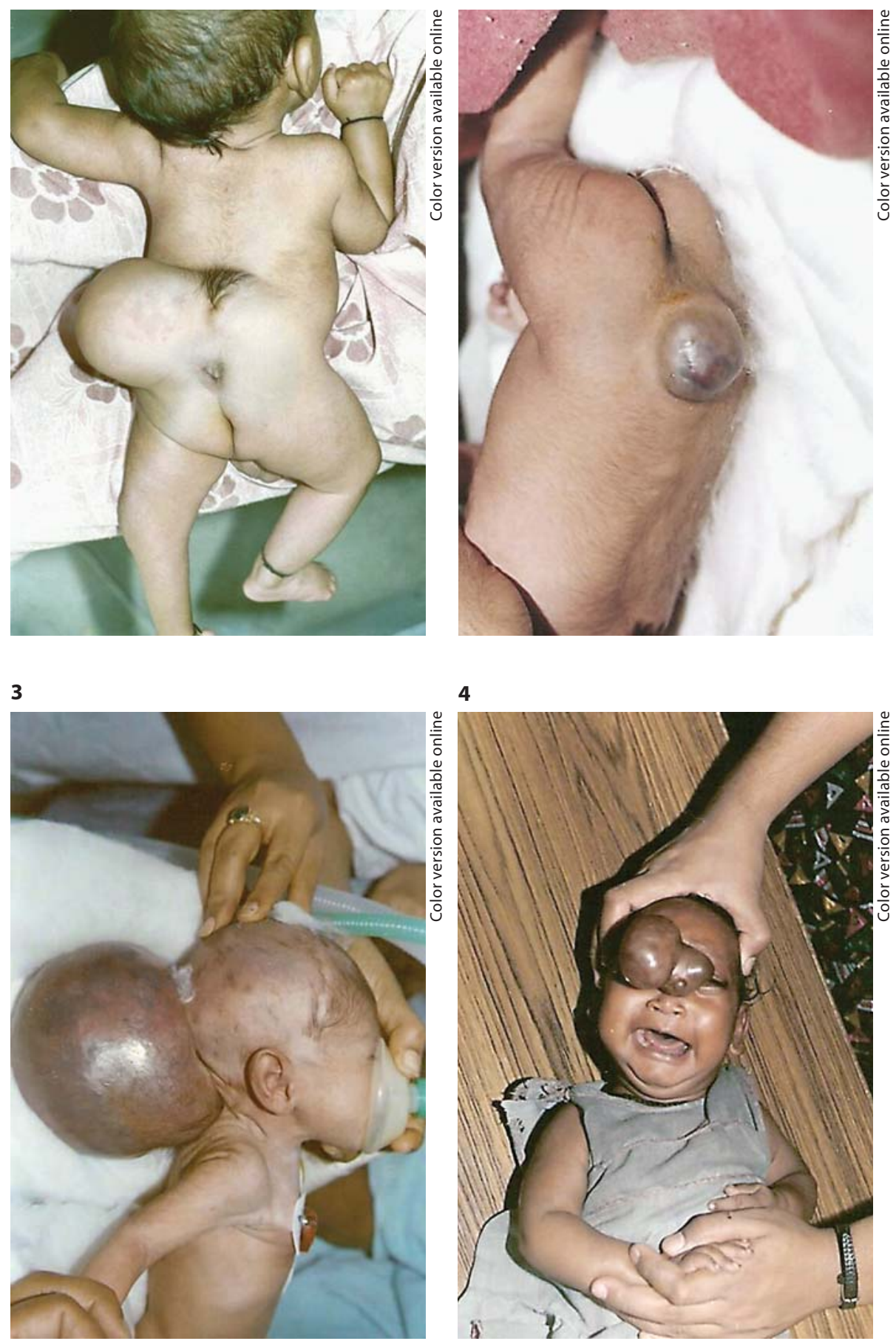

well as the CNS and non-neural malformations. The exact mechanism of NTDs is not known at present, but a range of mouse mutant models, especially the curly tail (ct) mutant which mimics human malformations in location, pathology and associated abnormalities and loop tail mutant which manifests into craniorachischisis, have greatly enhanced our understanding of NTDs in humans $[1,2]$. Several excellent reviews from time to time have elaborated the role of different genes in the neurulation process in general as well in folate metabolism pathway [3-8]. Extracellular matrix, cell surface glycoproteins, actin-containing microfilaments, growth factors and coor- 
dinated action of several genes have been implicated in the neurulation process. Until 2007, 190 naturally occurring or experimentally induced mouse mutants with NTDs had been described and on the basis of available literature on NTD producing loss of function mutations in mice, 28 genes are believed to be required for normal neurulation [9]. NTDs can also be produced surgically. Models based on mechanically induced NTDs due to disruption of normal neurulation through surgical intervention offers advantages to toxin-induced NTDs. The neurological evaluations demonstrated normal functioning in the large animals in which MMC could be mechanically created and surgically repaired $[7,8]$.

At present, oral folic acid intake remains the treatment of choice to prevent NTDs. Folic acid supplementation has been implicated in prevention of not only NTDs but also orofacial anomalies. A good deal of literature substantiates the role of folic acid in preventing preterm delivery, placental abruptions and infarctions. Periconceptional intake of multivitamins containing folic acid reduces the risk of having NTD in previously affected pregnancy. Recent literature suggests inositol as a possible adjunct to folic acid therapy $[10,11]$. Complementary and alternative medicine therapy has been used in several diseases including spina bifida. Cordyceps, Ocimum sanctum, Azadirachta indica and other medicinal plants and their extracts which are reported to have immunomodulating, anti-cancer and multiple rejuvenating effects, may be investigated in NTD mutant mice in combination with stem cells [12].

At present the only option for prenatal therapy of spina bifida is fetal surgery, which remains under investigation in the Management of Myelomeningocele Study (MOMS) trial. Fichter et al. [13] have reviewed fetal spina bifida repair in great detail and have concluded that despite possible risks for fetus and mother, intrauterine MMC repair may prove to be beneficial in the fetuses before 26 weeks of gestational age, with small ventricles at the time of surgery, and lesion levels below L2. However, the chances for success of fetal surgery are probably very limited and it will remain a very aggressive option which is likely to be poorly accepted by most patients.

\section{Stem Cell Therapy}

Stem cells have emerged as a potential therapeutic modality for several diseases due to their reparative function. They are unspecialized cells which virtually can give rise to many or all of the different cell types in the body. In recent years their therapeutic role has been investigated in treating a range of neurodegenerative diseases including stroke, cerebral palsy, spinal cord injury, post-polio syndrome, musculoskeletal disorders and congenital malformations.

Sim et al. [14] investigated the chronological changes of reclosure capacity in surgically induced spinal ONTDs of chick embryos. The chronological changes in reclosure capacity of ONTDs paralleled the proliferative activity of the neural tube, suggesting that manipulation of cell dynamics could enhance the reclosure process in embryonic spinal cord tissue. Extending these studies, Lee et al. [15] have reported enhancement of reclosure capacity by the intra-amniotic injection of human embryonic stem cells (hESCs) in surgically induced spinal ONTDs in chick embryos. The study reveals the possibility of use of hESCs in prenatal management of human NTDs. The experiment included longitudinal opening of neural tubes of chick embryos at the wing bud level for a length of six somites. hESCs were injected into the amniotic cavity with the aid of vehicle. Neural tube incision followed quick injection of $2 \mu \mathrm{l}$ of vehicle or hESC solution. The sizes of NTDs on postoperative reincubation days 3,5 and 7 were compared between control (no injection) and vehicle (injection of glucose in PBS and hESC injection of hESCs in vehicle) groups. The postoperative day (POD) lengths were significantly smaller in the hESC cell group than in control and vehicle groups from POD 3 to POD 7, clearly demonstrating enhanced reclosure of the ONTDs with embryonic stem cells. The enhancement of reclosure capacity in this study could be due to the bridging effect required to fill the injury site and protect injured tissue to promote regeneration which in turn might have led to repair of structures and regain of function. To simulate the clinical situation of human NTDs, Lee et al. [24] further investigated reclosure of surgically induced spinal ONTDs by intra-amniotic injection of hESCs in chick embryos $24 \mathrm{~h}$ after lesion induction. The hESCs injected into the amniotic cavity at $24 \mathrm{~h}$ after ONTD induction enhanced reclosure ability.

Gupta et al. [16] performed a study with autologous stem cells in congenital anomalies on 17 patients with meningomyelocele. Stem cells were administered either during definitive surgery or postoperatively. CD34+ mononuclear cells separated from bone marrow were injected into the spinal cord and caudal space for meningomyelocele. The condition of the patient before surgery served as the control condition for that patient. Temperature charting and seeking evidence of infection or other complications were used as postoperative monitoring measures. In 
meningomyelocele, antibiotic coverage was given for 7-10 days. Clinical status and muscle charting of meningomyelocele patients were evaluated by two independent physiotherapists. Changes in power, sensation, and neurological status of bladder and bowel were examined. Patients in the study were of age group 0-1 month, 1-5 months, and 1-6 years in 6, 8 and 3 cases, respectively, and a history of rupture was present in 5 patients. Meningomyelocele repair had been performed in 4 patients in the past who presented persistent neurological deficiency. In 1 patient redo surgery for a tethered cord had been performed. In 13 patients, meningomyelocele repair and stem cell injection were performed whereas in 3 patients only stem cell injection was given. Two patients had meningoceles. A smooth postoperative recovery in all subjects was recorded without complications. The initial results had been promising but the authors warrant long-term evaluation with randomized control trials to draw significant conclusions. Although the work is of significant value, being the first of its kind from India, experts in the field believe that this study is not without flaws because: (1) a traumatic paraplegia rat model cannot be a basis of meningomyelocele experimentations in humans since neurons are normal until injury in traumatic paraplegia whereas in meningomyelocele, neurons are congenital dysphasic; (2) the authors failed to demonstrate if the injected stem cells could really form functional neurons after transplantation; (3) the safety of the cells for human use was not ensured as they could become tumorigenic, and finally (4) because of the lack of proper assessment of recovery of function, especially in very small infants.

Fauza et al. [17] delivered neural stem cells (NSCs) to the spinal cord in lambs with experimental MMC as an adjuvant to fetal repair of spina bifida. The study included fetal lambs divided in three groups: group I animals had animals without repair; group II presented standard surgical MMC coverage, and group III had MMC coverage plus delivery of a murine NSC clone into the spinal cord defect. A $2 \mathrm{ml} \mathrm{NSC}$ suspension of $10^{8}$ cells $/ \mathrm{ml}$ was directly injected into the gray matter of the spinal cord at 4-6 equally spaced points. Animals in group II and III showed higher survival than group I. Animals in group I also presented inability to walk (major paraparesis) to a more significant extent than in groups II and III. A lower incidence of major paraparesis was recorded in group III compared to group II, but the results were not statistically significant. Group III, comprising animals without engraft, showed no indications of clinical worsening or impairment greater than animals in groups I and II. Group III presented increased power of muscular contractions and tactile function in the affected areas compared to group II. In all animals in groups II and III, variable degrees of spinal cord tethering to the alloderm patch was recorded. Despite their xenologous origin and lack of host immunosuppression, all animals in group III showed NSC engraftment and survival in the spinal cord and no worsening from the existing condition was observed. Results showed noticeably higher NSC density within the most damaged portions of the spinal cord, suggesting selective NSC homing to abnormal areas. This effect was distinct in the periphery of the cord at the level of the defect where cord had been exposed to chemical insult from the amniotic fluid and possibly suffered mechanical damage. In hydro/syringomyelia-like lesions present within the cord of some of the animals in this group, some donor cells were found which mostly occur in MMC. This could be the consequence of needle-based cell injection in this model. There were very few non-peripheral areas with no morphologic evidence of injury with any engrafted cells. The authors did not find any clear relationship between the degree of NSC engraftment and clinical outcome in this initial series. No evidence of tumor formation was recorded at the engrafted sites in any of the animals. The study clearly pointed towards some role of NSCs in the regenerative process. The authors suggested validation of the effect with more experiments before NSC could be used as therapeutic modality.

\section{Induced Pluripotent Stem Cells}

First described by Takahashi and Yamanaka [18], these cells are basically reprogrammed somatic cells which eventually become pluripotent by introduction and ectopic expression of some specific transcription factors Oct4, Sox2, Klf4 and Myc being the most prominent. Induced pluripotent stem cells (iPSCs) share many similarities with hESCs and can differentiate into all major cell types representing three embryonic germ layers. This breakthrough technology on the one hand has circumvented the use of embryos and oocytes for research, on the other the use of animals can be spared significantly for drug discovery and toxicity testing. Generation of patient-specific iPSCs further bypass the problem of graft rejection thus proving to be an ideal choice for transplantation studies. In addition, iPSCs are capable of restoring organ function as well as reconstruction of the entire tissue in the event of injury or disease.

The discovery of iPSCs has initiated a flurry of research on finding treatment for a variety of CNS disor- 
ders. Recently it has become possible to generate subjectspecific iPSCs which can further differentiate into relevant cell types $[19,20]$. Some recent examples include generation of spinal motor neurons and glia from a person suffering from amyotrophic lateral scelerosis, dopamine neurons derived from iPSCs derived from persons with Parkinson's disease, motor neurons derived from iPSCs derived from a 3-year-old child with spinal muscular atrophy and derivation of iPSCs from persons with familial dysautonomia - a rare genetic disease mainly affecting the peripheral nervous system [21-24].

Due to a direct role of cranial neural crest cells in neural tube closure, it is fairly reasonable to hypothesize that probably neural crest cells can be reprogrammed to derive specific NTD iPSCs which, if transplanted, could possibly adequately help in closure of neural tubes in young infants. For caution, such studies should first be demonstrated in animal models. To model the disease in vitro, neural crest stem cells can be isolated from adult palatum [25]. For rapid and successful replenishment of the diseased tissue with healthy cells, the migratory potential of such neural crest iPSCs need to be accessed and their dependency on extracellular matrix molecules, such as thrombospondin for migration, examined. Another candidate cell type for iPSCs therapy in NTD can be liver cells as these cells are a natural source of folic acid. This fact can be used in helping women with a family history of birth defects or with a previous child with a birth defect or multiple first-trimester abortions. Liver cells isolated from such a woman can be reprogrammed to endogenously secrete folic acid and administered right before the onset of pregnancy as a prophylactic measure to possibly prevent NTD in the newborn. But again, this idea is purely speculative and needs proper experimental validation, especially for their responsiveness to indigenous folate synthesis, absorption and transport as well as folate toxicity (in the event of excessive synthesis of folic acid).

iPSCs are unique in the sense that patient-specific cells can differentiate into specific cell lineages, thus providing a potential in vitro tool to study the complexity of the disease. The only concern with iPSCs at present is their safety for human use as misprogrammed and undifferentiated iPSCs may lead to tumors.

\section{New Therapies}

The marriage between chemical biology and molecular genetics has led to the emergence of a new discipline of chemical genomics aimed at discovering therapeutic small molecules. A range of molecules including antisense oligonucleotides, peptides, small interfering (si) RNAs and microRNAs, CNS, dopaminergic, and natural product-based drug candidates. Zhou et al. [26] tested peptidergic agonists of activity-dependent neurotrophic factor on prenatal alcohol-induced NTDs and serotonin neuron loss in time pregnant $\mathrm{B} 6 \mathrm{dams}$. The authors experimentally induced deficits in fetal 5-HT neurons in the caudal raphe through prenatal exposure to alcohol. Prenatal treatment with the neuroprotective peptides SAL or NAP could fully protect against reduction in 5-HT neurons in the caudal and rostral raphe, and NAP prevented delayed closing of the rhombencephalic ventral canal. A recent study by Zwerts et al. [27] has demonstrated the role of endothelial cell survivin in embryonic defects in angiogenesis, cardiogenesis, and neural tube closure. Survivin is an inhibitor of apoptosis protein which is a regulator of mitosis and is highly expressed in proliferating cells but low or absent in quiescent or terminally differentiated cells. It is a negative regulator of apoptosis and plays a critical role in maintaining prenatal vascular integrity. Their study showed that lack of endothelial surviving expression during embryonic development resulted in delayed neural tube closure along with in utero lethality and defective cardiac development. The offspring of diabetic mothers are more prone to congenital malformations. Wentzel el al. [28] have shown that the teratogenic effect of diabetic serum can be prevented by supplementation of superoxide dismutase and $\mathrm{N}$-acetylcysteine in rat embryo culture. Small molecules such as monastrol or ispinesib, which can inhibit kinesin KIF11 and inhibitor of $\alpha 4$ integrin (CT301) which have shown to have neuroprotective function, may be investigated for their possible role in preventing NTDs. Gyuris et al. [29], using bromodomain-containing protein 2 (Brd2) null mice, have shown that $\mathrm{Brd} 2$ is required for neural tube closure and embryogenesis. The authors have nicely demonstrated that the disruption of Brd2 gene causes embryonic lethality and exhibits neural tube closure defects and most commonly the anencephaly of the hindbrain. The effect of transgenic Brd2 gene activity may be tested on neural tube closure to investigate if $\mathrm{Brd} 2$ gene overexpression could be used as a therapeutic target. Watson et al. [30] have shown that Mrj-/- mouse embryos exhibit NTDs independent of extraembryonic defects. The study suggests using Mrj-/- mutant embryos as an excellent model to study the relationship between stem cell selfrenewal and neural tube closure. Neural stem cells with possible Mrj reprogramming for increased self-renewal can be a viable option for development of stem cell-based 
therapy for NTDs. A recent revelation that synergistic inhibition of SMAD signaling by Noggin and SB431542 can cause efficient neural conversion of hESCs as well as direct differentiation of iPSCs into midbrain dopamine and spinal motor neurons, further envisage the possible scope of use of small molecules and stem cells for treating NTDs [31]. In a recent study, Camerer et al. [32] have demonstrated that local protease signaling contributes to neural tube closure in the mouse embryos. These signaling molecules can be exploited for their therapeutic suitability as target molecules in the treatment of neural tube and associated developmental defects. In addition, siRNAs and microRNAs, designed against a specific gene, that regulate developmental processes may be helpful in understanding the underlying cause of NTDs and in developing therapeutic strategies to prevent NTDs.

\section{Conclusion}

NTDs are preventable to some extent by proper consumption of folic acid. The newer treatment modalities with stem cells though demonstrate some improvement, but for safety, rigorous animal experimental studies are advised before their use in human clinical trials. Before starting any such study, investigators should carefully design the experiment, keeping in mind all the considerations such as the use of proper controls, use of correct and appropriate experimental models, use of well-standardized and established procedures (especially when human subjects are involved) and proper tests to access the recovery of function. Assessment of migration and functional integration of stem cells should be thoroughly investigated in studies involving cell transplantation studies. The use of magnetic resonance imaging and nanotechnology procedures has been immensely helpful in tracing the fate of transplanted stem cells [33-36]. Alternative medicine in conjunction with stem cells and iPSCs may be useful in treating NTDs. Combination therapies using stem cells with plant extracts of known potential therapeutic value can be tested in animal models of NTD, to examine the therapeutic effect of such formulations.

\section{Acknowledgement}

The authors thank Dr. Karvita Ahluwalia for her comments and suggestions.

\section{References}

1 Neumann PE, Frankel WN, Letts VA, Coffin JM, Copp AJ, Bernfield M: Multifactorial inheritance of neural tube defects: localization of the major gene and recognition of modifiers in ct mutant mice. Nat Genet 1994;6: 357-362.

-2 Murdoch JN, Doudney K, Paternotte C, Copp AJ, Stanier P: Severe neural tube defects in the loop - tail mouse result from mutation of Lppl, a novel gene involved in floor plate specification. Hum Mol Genet 2001; 10: 2593-2601.

-3 Joó JG: Recent perspectives on the genetic background of neural tube defects with special regard to iniencephaly. Expert Rev Mol Diagn 2009;3:281-293.

$\checkmark 4$ Colas JFC, Schoenwolf GC: Towards a cellular and molecular understanding of neurulation. Dev Dyn 2001;221:117-145.

5 Sadler TW: Embryology of neural tube development. Am J Med Genet C Semin Med Genet 2005;135:2-8.

6 Gos M, Potocka AS: Genetic basis of neural tube defects. I. Regulatory genes for the neurulation process. J Appl Genet 2002;43:343350.

7 Finnell RH, Gould A, Spiegelstein O: Pathobiology and genetics of neural tube defects. Epilepsia 2003;44(suppl 3):14-23.
8 Manning SM, Jennings R, Madsen JR: Pathophysiology, prevention, and potential treatment of neural tube defects. Ment Retard Dev Disabil Res Rev 2000;6:6-14.

-9 Kibar Z, Capra V, Gros P: Toward understanding the genetic basis of neural tube defects. Clin Genet 2007,71:295-310.

10 Copp AJ: Prevention of neural tube defects: vitamins, enzymes and genes. Curr Opin Neurol 1998;11:97-102.

11 Greene NDE, Copp AJ: Mouse models of neural tube defects: investigating preventive mechanisms. Am J Med Genet C Semin Med Genet 2005;135:31-41.

12 Brown KA, Patel DR: Complementary and alternative medicine in developmental disabilities. Indian J Pediatr 2005;72:949-952.

- 13 Fichter MA, Dornseifer U, Henke J, Schneider KT, Kovacs L, Biemer E, Bruner J, Adzick NS, Harrison MR, Papadopulos NA: Fetal spina bifida repair - current trends and prospects of intrauterine neurosurgery. Fetal Diagn Ther 2008;23:271-286.

14 Sim KB, Cho BK, Lee YJ, Lee MS, Wang KC: Chronological changes of reclosure capacity in surgically induced spinal open neural tube defects of chick embryos. Neurosci Lett 2000;292:151-154.
15 Lee DH, Kim EY, Park S, Phi JH, Kim SK, Cho BK, Lim J, Wang KC: Reclosure of surgically induced spinal open neural tube defects by the intra-amniotic injection of human embryonic stem cells in chick embryos 24 hours after lesion induction. Neurosurgery 2006;105(suppl):127-133.

16 Gupta DK, Sharma S, Venugopal P, Kumar L, Mohanty S, Dattagupta S: Stem cells as a therapeutic modality in pediatric malformations. Transplant Proc 2007;39:700-702.

17 Fauza DO, Jennings RW, Teng YD, Synder EY: Neural stem cell delivery to the spinal cord in an ovine model of fetal surgery for spina bifida. Surgery 2008;144:367-373.

18 Takahashi K, Yamanaka S: Induction of pluripotent stem cells from mouse embryonic and adult fibroblast cultures by defined factors. Cell 2006;126:663-676.

19 Park IH, Arora N, Huo H, Maherali N, Ahfeldt T, Shimamura A, Lensch MW, Cowan C, Hochedlinger K: Daley GQ, Disease-specific induced pluripotent stem cells. Cell 2008; 134:1-10.

20 Park IH, Lerou PH, Zhao R, Huo H, Daley GQ: Generation of human-induced pluripotent stem cells. Nat Protoc 2008:3:1180-1186. 
-21 Dimos JT, Rodolfa KT, Niakan KK, Weisenthal LM, Mitsumoto H, Chung W, Croft GF, Saphier G, Leibe R, Goland R, Wichterle H, Henderson CE, Eggan K: Induced pluripotent stem cells generated from patients with ALS also can be differentiated into motor neurons. Science 2008;321:1218-1221.

-22 Soldner F, Hockemeyer D, Beard C, Gao Q, Bell GW, Cook EG, Hargus G, Blak A, Cooper O, Mitalipova M, Isacson O, Jaenisch R: Parkinson's disease patient-derived induced pluripotent stem cells free of viral reprogramming factors. Cell 2009;136:964-977.

- 23 Ebert AD, Yu J, Rose FR Jr, Mattis VB, Lorson CL, Thomson JA, Svendsen CN: Induced pluripotent stem cells from a spinal muscular atrophy patient. Nature 2009;457:277280.

24 Lee G, Papapetrou EP, Kim H, Chambers SM, Tomishima MJ, Fasano CA, Ganat YM, Menon J, Shimizu F, Viale A, Tabar V, Sadelain M, Studer L: Modelling pathogenesis and treatment of familial dysautonomia using patient-specific iPSCs. Nature 2009;461: 402-408.

25 Widera D, Zander C, Heidbreder M, Kasperek Y, Noll T, Seitz O, Saldamli B, Sudhoff H, Sader R, Kaltschmidt C, Kaltschmidt B: Adult palatum as a novel source of neural crest related stem cells. Stem Cells 2009;27: 1899-1910.
26 Zhou FC, Fang Y, Goodlett C: Peptidergic agonists of activity-dependent neurotrophic factor protect against prenatal alcohol-induced neural tube defects and serotonin neuron loss. Alcohol Clin Exp Res 2008;32: 1361-1371.

27 Zwerts F, Lupu F, De Vriese A, Pollefeyt S, Moons L, Altura RA, Jiang Y, Maxwell PH, Hill P, Hideyasu OH, Rieker C, Collen DS, Conway SJ, Conway EM: Lack of endothelial cell survivin causes embryonic defects in angiogenesis, cardiogenesis, and neural tube closure. Blood 2007;109:4742-4752.

28 Wentzel P, Thunberg L, Eriksson UJ: Teratogenic effect of diabetic serum is prevented by supplementation of superoxide dismutase and $\mathrm{N}$-acetylcysteine in rat embryo culture. Diabetologia 1997;40:7-14.

29 Gyuris A, Donovan DJ, Seymour KA, Lovasco LA, Smilowitz NR, Halperin ALP, Klysik JE, Freiman RN: The chromatin targeting protein $\mathrm{Brd} 2$ is required for neural tube closure and embryogenesis. Biochim Biophys Acta 2009;1789:413-421.

-30 Watson ED, Mattar P, Schuurmans C, Cross JC: Neural stem cell self-renewal requires the Mrj co-chaperone. Dev Dyn 2009;238:25642574.
31 Chambers SM, Fasano CA, Papapetrou EP, Tomishima M, Sadelain M, Studer L: Highly efficient neural conversion of human ES and iPS cells by dual inhibition of SMAD signaling. Nat Biotechnol 2009;27:275-280.

- 32 Camerer E, Barker A, Duong DN, Ganesan R, Kataoka H, Cornelissen I, Darragh MR, Hussain A, Zheng YW, Srinivasan Y, Brown C, Xu SM, Regard JB, Lin CY, Craik CS, Kirchhofer D, Coughlin SR: Local protease signaling contributes to neural tube closure in the mouse embryo. Dev Cell 2010;18:2538.

33 Modo M, Cash D, Mellodew K, Williams SC, Fraser SE, Meade TJ, Price J, Hodges H: Tracking transplanted stem cell migration using bifunctional, contrast agent-enhanced, magnetic resonance imaging. Neuroimage 2002;17:803-811.

34 Pearl J, Wu JC: Seeing is believing: tracking cells to determine the effects of cell transplantation. Semin Thorac Cardiovasc Surg 2008:20:102-109.

35 Ferreira L, Karp JM, Nobre L, Langer R: New opportunities: the use of nanotechnologies to manipulate and track stem cells. Cell Stem Cell. 2008;3:136-146.

36 Syková E, Jendelová P, Herynek V: MR Tracking of stem cells in living recipient. Methods Mol Biol 2009;549:197-215. 